\title{
ĐÁNH GIÁ ĐỘ SÂU BẢN ĐỒ ĐỊA HÌNH ĐÁY BIỂN VÀ HẢI ĐỒ DỰA TRÊN CÁC MÔ HİNH MẠTT BIỄN
}

\author{
LƯƠNG THANH THẠCH(1), TRÀ̀N VĂN HẢI ${ }^{(2)}$, \\ NGUYẼ̃N TH!̣ HỒNG ${ }^{(3)}$, ĐỖ VĂN MONG ${ }^{(4)}$ \\ ${ }^{(1)}$ Truoòng Đại học Tài nguyên và Môi truoòng Hà Nội \\ ${ }^{(2)}$ Xi nghiệp Trắc địa, Công ty TNHH MTV Trắc địa Bản đồ \\ (3) Truò̀ng Đại học Hàng hải Việt Nam \\ ${ }^{(4)}$ Đoàn Đo đạc Biên vẽ hải đồ và Nghiên cứu biển
}

\section{Tóm tắt:}

Bài báo khoa học này trình bày kết quả xây dụng mô hình mặt biển thấp nhất khu vực trên vùng biển Việt Nam và sủ dụng mô hình mặt biển trung bình khu vưc và mô hình mặt biển thấp nhất khu vục để đánh giá sụ phù hợp của dũ liệu độ sâu bản đồ địa hình đáy biển và độ sâu hải đồ trong bài toán xác định độ sâu bản đồ địa hình đáy biển tù độ sâu hải đồ.

\section{1. Đặt vấn đề}

Theo quy định về cơ sở toán học [2], bản đồ địa hình đáy biển được thể hiện như là sự kéo dài về phía biển của bản đồ địa hình quốc gia trên đất liền. Vì vậy,bản đồ địa hình đáy biển (ĐHĐB) cùng với bản đồ địa hình quốc gia trên đất liền tạo thành một hệ thống nhất cả về hệ quy chiếu, hệ tọa độ và hệ độ cao, cả về nội dung và cách biểu thị các đối tượng địa lý. Bản đồ ĐHĐB giữ vai trò quan trọng trong sự nghiệp xây dựng và phát triển kinh tế xã hội trên biển; là cơ sở để thiết kế xây dựng các công trình ven biển và trên các đảo, quần đảo; phát triển ngư trường; quy hoạch các tuyến vận tải biển; nghiên cứu môi trường; thăm dò và khai thác dầu khí;... Đối tượng địa lý quan trọng nhất trên bản đồ ĐHĐB là độ sâu ĐHĐB. Đối với ngành Trắc địa Bản đồ, bản đồ ĐHĐB được sử dụng làm nền thông tin địa lý biển, còn độ sâu ĐHĐB là đối tượng quan trọng để quy chiếu các trị đo trọng lực biển.

Bản đồ địa hình đáy biển do Trung tâm Trắc địa Bản đồ biển, Tổng cục Biển và Hải đảo Việt Nam thành lập dựa trên hệ tọa độ VN2000, phép chiếu UTM, hệ độ cao HP72 ở các dãy tỷ lệ 1:5.000, 1:10.000 cho các đảo và các khu vực kinh tế trọng điểm gần bờ, 1:50.000 cho các vùng biển ven bờ (phạm vi phủ đến hết vùng tiếp giáp lãnh hải). Trong gần 30 năm đo đạc ĐHĐB, đến nay bản đồ ĐHĐB mới chỉ phủ kín được khoảng 20\% diện tích vùng biển Việt Nam.

Hải đồ là tài liệu quan trọng bảo đảm định vị, dẫn đường an toàn cho các phương tiện hoạt động trên biển; phục vụ phân định ranh giới giữa các vùng biển; bảo đảm quốc phòng, an ninh và tìm kiếm, cứu hộ cứu nạn; góp phần khẳng định và bảo vệ chủ quyền quốc gia trên biển;... Hải đồ trên vùng biển Việt Nam được Đoàn Đo đạc Biên vẽ hải đồ và Nghiên cứu biển (Đoàn 6) thành lập dựa trên hệ tọa độ VN2000 (2002 2009) và quốc tế WGS84 (2010 đến nay), phép chiếu Mercator, hệ độ cao tính theo mực nước triều thiên văn thấp nhất ở các dãy tỷ lệ: $1: 1.000$, $1: 2.000,1: 5.000,1: 10.000$ và $1: 25.000$ cho các khu vực cảng biển, đảo/đá; 1:100.000, $1: 200.000,1: 300.000,1: 400.000,1: 500.000$, $1: 1.000 .000,1: 1.500 .000$ và $1: 2.500 .000$ cho toàn bộ vùng biển Việt Nam.

Do thiếu độ sâu bản đồ ĐHĐB để thực hiện các nhiệm vụ khoa học kỹ thuật và thực tiễn nên một số cơ quan chuyên ngành đã tổ chức nghiên cứu chuyển đổi độ sâu hải đồ về độ sâu bản đồ ĐHĐB. Tuy nhiên, chưa có công trình nào đáp ứng được yêu cầu cả về cơ sở khoa học, cả về độ chính xác của độ sâu bản đồ ĐHĐB. 
Nhằm thiết lập cơ sở toán học cho cơ sở dữ liệu nền thông tin địa lý biển và quy chiếu các trị đo sâu ĐHĐB, đồng thời tạo tiền đề để giải quyết bài toán nêu trên và các nhiệm vụ khoa học và thực tiễn liên quan đến độ sâu ĐHĐB, dựa vào kết quả nghiên cứu khoa học của công trình [4], mô hình địa hình động lực trung bình DTU10MDT và độ cao mặt biển trung bình tại 36 trạm nghiệm triều dọc bờ biển và trên một số đảo của Việt Nam [4], công trình [5] đã xây dựng mô hình mặt biển trung bình khu vực (MDTTBKV) trên vùng biển Việt Nam. Dựa vào độ cao mặt biển thấp nhất tại 36 trạm nghiệm triều [4] và độ chênh giữa mặt biển trung bình và mặt biển thấp nhất khu vực tại 29 trạm nghiệm triều do Đoàn 6 đo đạc trong giai đoạn 2001-2010, công trình [5] cũng đã xây mô hình mặt biển thấp nhất khu vực (MBTNKV65) trên vùng biển Việt Nam. Sử dụng độ chênh đo giữa mặt biển trung bình và mặt biển thấp nhất khu vực tại 23 trạm nghiệm triều dọc bờ biển và trên một số đảo của Việt Nam (hình 1b), công trình [5] đã đánh giá độ chính xác độ chênh giữa mô hình MDTTBKV và mô hình MBTNKV65 đạt $\pm 0,157 \mathrm{~m}$.

Bài báo khoa học này khai thác một khía cạnh khác của các mô hình mặt biển, trên cơ sở đề xuất phương pháp xác định độ sâu bản đồ ĐHĐB từ độ sâu hải đồ và đánh giá dữ liệu độ sâu bản đồ ĐHĐB và độ sâu hải đồ trên vùng biển Việt Nam.

\section{Giải quyết vấn đề}

\subsection{Số liệu sử dụng}

Mô hình mặt biển thấp nhất trên toàn bộ vùng biển Việt Nam được xây dựng bằng số liệu từ các nguồn sau:

- Toàn bộ số liệu đã sử dụng để xây dựng mô hình mặt biển trung bình khu vực và mô hình mặt biển thấp nhất khu vực trên vùng biển Việt Nam trong các công trình $[4,5]$;

- Độ chênh giữa mặt biển trung bình và mặt biển thấp nhất khu vực tại các trạm nghiệm triều do Đoàn 6 thực hiện trong giai đoạn 2011 - 2017 (xem hình $1 \mathrm{a}$ và cột $1-4$, bảng 2 ). Các trạm sử dụng để kiểm tra độ chính xác của mô hình được lấy từ công trình [5] (xem hình $1 b$ ).

- Bản đồ địa hình đáy biển tỷ lệ 1:50.000 do Trung tâm Trắc địa Bản đồ biển, Tổng cục Biển và Hải đảo Việt Nam sản xuất trong các năm 2007-2008 (xem bảng1).

- Hải đồ tỷ lệ 1:100.000 do Đoàn 6 sản xuất trong các năm 2002-2011 (xem bảng1).

Sơ đồ vị trí các mảnh bản đồ ĐHĐB và hải đồ được thể hiện trên hình 2.

\subsection{Kiểm tra sai số hệ thống trong độ chênh đo tại các trạm nghiệm triều}

Để nâng cao độ chính xác của mô hình mặt biển thấp nhất trên vùng biển Việt Nam, chúng

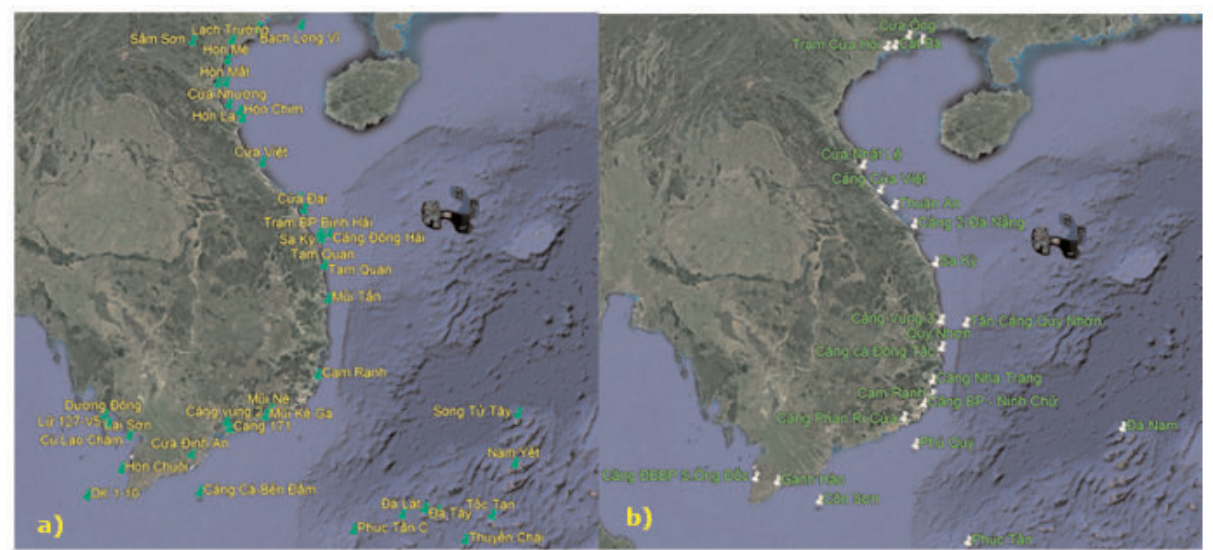

Hình 1: So đồ vị trí các trạm nghiệm triều trên vùng biển Việt Nam giai đoạn 2011 - 2017

a) Các trạm nghiệm triều xây dụng mô hình; b) Các trạm nghiệm triều kiểm tra [5] 
tôi bổ sung thêm 43 trạm nghiệm triều được Đoàn 6 đo đạc trong giai đoạn 2011-2017. Tuy nhiên, cần kiểm tra độ tin cậy của các trị đo tại 43 trạm nghiệm triều này.

Dựa trên mô hình MDTTBKV và MBTNKV65 đã được xây dựng trong công trình [5], chúng tôi xác định độ chênh giữa MDTTBKV và MBTNKV65 (độ chênh giữa $A 0$ và p0) tại 43 trạm nghiệm triều và so sánh với độ chênh đo. Kết quả kiểm tra sai số hệ thống trong độ chênh đo tại 43 trạm nghiệm triều dựa trên các mô hình MDTTBKV, MBTNKV65 được thể hiện trong bảng 2 .

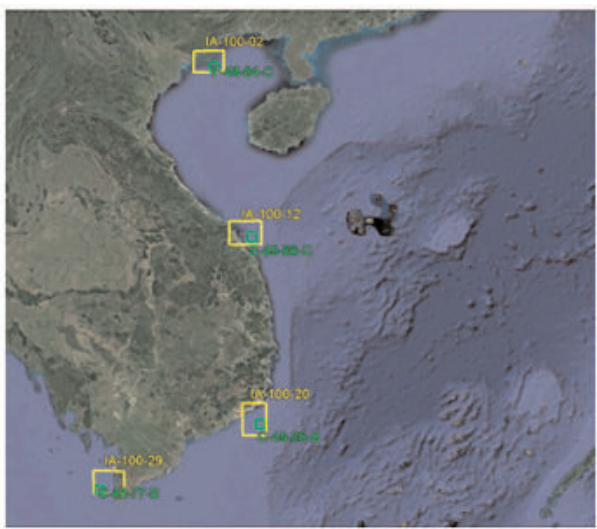

Hình 2: So đồ vị trí các mảnh bản đồ ĐHĐB và hải đồ phục vu tính toán thử nghiệm

Kết quả kiểm tra sai số hệ thống

$$
A=\sum_{i=l}^{43} d_{i}=1.395 \mathrm{~m}, B=\sum_{i=l}^{43}\left|d_{i}\right|=6.077 \mathrm{~m} .
$$

Do $|A|=1.395<0.25 \times B=1.519$ nên trong hai dãy giá trị độ chênh (A0- $\pi 0)$ không chứa sai số hệ thống và hoàn toàn đảm bảo độ tin cậy để đưa vào xây dựng mô hình mặt biển thấp nhất khu vực trên vùng biển Việt Nam.

\subsection{Xây dụng mô hình mặt biển thấp nhất khu vẹc}

Mô hình mặt biển thấp nhất khu vực trên vùng biển Việt Nam được xây dựng bằng phương pháp đã được trình bày trong công trình [5], mô hình mặt biển thấp nhất khu vực MBTNKV65, độ chênh giữa mặt biển trung bình và mặt biển thấp nhất khu vực tại 43 trạm nghiệm triều trong bảng 2 và Thuật toán loang (Spline with barriers) trong phần mềm ArcGis. Mô hình mặt biển thấp nhất khu vực vừa được xây dựng gọi là mô hình MBTNKV108 (xem hình 3).

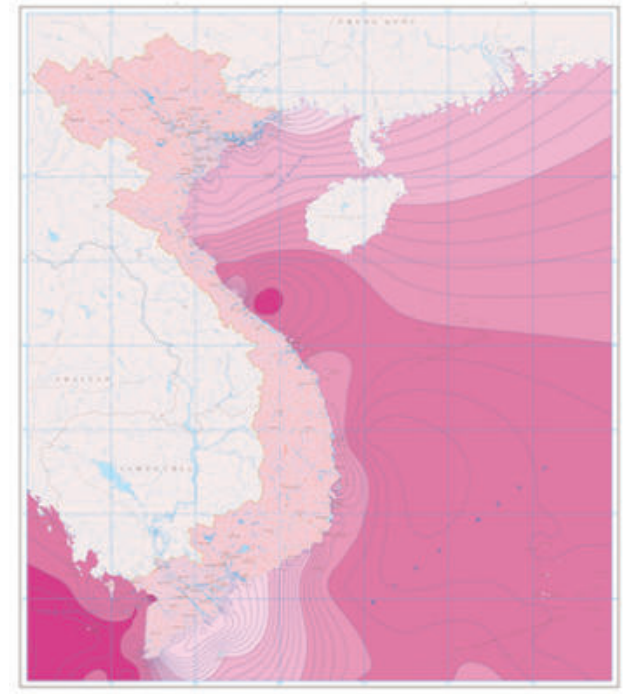

Hình 3: Hình ảnh của mô hình MBTNKV108 trên vùng biển Việt Nam

Bảng 1: Thông tin về các mảnh hải đồ và bản đồ ĐHĐB phục vu tính toán thực nghiệm

\begin{tabular}{|c|c|c|c|c|c|}
\hline \multicolumn{3}{|c|}{ Hải đồ tỷ lệ $1: 100.000$} & \multicolumn{3}{|c|}{ Bàn đồ địa hình đáy biền tỷ lệ 1:50.000 } \\
\hline Khu vực & Phiên hiệu & $\begin{array}{l}\text { Năm sàn } \\
\text { xuất }\end{array}$ & Khu vực & $\begin{array}{l}\text { Phiên hiệu } \\
\text { Tên mành }\end{array}$ & $\begin{array}{l}\text { Năm sàn } \\
\text { xuất }\end{array}$ \\
\hline $\begin{array}{l}\text { Từ Đào Thanh Lam } \\
\text { đến đào Long Châu }\end{array}$ & IA-100-02 & 2007 & Quàng ninh - Vân Đồn & F-48-84-C & 2003 \\
\hline $\begin{array}{l}\text { Từ Vịnh Đà Nẵng } \\
\text { đến Cửa Đại }\end{array}$ & IA- $100-12$ & 2008 & TP Đà Nẵng & $\begin{array}{c}\text { E-49-86-C } \\
(6741 \mathrm{II})\end{array}$ & 2002 \\
\hline $\begin{array}{l}\text { Từ mũi Cà Ná đến } \\
\text { vịnh Phan Rí }\end{array}$ & IA- $100-20$ & 2007 & Bình Thuận -Bến Tre & $\begin{array}{c}\text { C-49-26-B } \\
\text { (6730 I) }\end{array}$ & 2009 \\
\hline $\begin{array}{l}\text { Từ Hòn Đá Bạc đến } \\
\text { Hòn Chuối }\end{array}$ & IA-100-29 & 2008 & Cà Mau & $\begin{array}{l}\text { C-48-77-B } \\
(5826 \mathrm{I})\end{array}$ & 2011 \\
\hline
\end{tabular}


Bảng 2: Kết quả kiểm tra sai số hệ thống trong độ chênh đo tại 43 trạm nghiệm triều

\begin{tabular}{|c|c|c|c|c|c|c|c|}
\hline STT & Tên trạm & $\begin{array}{c}\text { Năm } \\
\text { đo }\end{array}$ & $\begin{array}{r}\text { A0- } \pi 0 \\
\text { đo (m) }\end{array}$ & $\begin{array}{c}\text { Độ cao } \\
\text { MDTTBKV } \\
\text { (m) }\end{array}$ & $\begin{array}{c}\text { Độ cao } \\
\text { MBTNKV65 } \\
\text { (m) }\end{array}$ & $\begin{array}{c}\mathbf{A} 0-\pi 0 \\
\text { tính } \\
(\mathrm{m})\end{array}$ & $\begin{array}{c}d_{i}= \\
(7)-(4)\end{array}$ \\
\hline (1) & (2) & (3) & (4) & (5) & (6) & (7) & (8) \\
\hline 1 & Cửa Nhượng - Hà Tĩnh & 2011 & 1.33 & 0.110 & -1.451 & 1.561 & -0.231 \\
\hline 2 & Cảng 171 - Vũng Tàu & 2011 & 2.42 & -0.116 & -2.446 & 2.330 & 0.090 \\
\hline 3 & Dương Đông -Phú Quốc & 2011 & 0.71 & -0.193 & -0.625 & 0.432 & 0.278 \\
\hline 4 & Cửa Định An - SócTrăng & 2011 & 2.42 & 0.086 & -2.574 & 2.660 & -0.240 \\
\hline 5 & Đá Tây - Trường Sa & 2011 & 1.18 & 0.208 & -0.943 & 1.151 & 0.029 \\
\hline 6 & Đá Đông - Trường Sa & 2011 & 1.18 & 0.208 & -0.934 & 1.142 & 0.038 \\
\hline 7 & Ba Lạt - Thái Bình & 2012 & 1.92 & 0.121 & -2.119 & 2.240 & -0.320 \\
\hline 8 & Lạch Trường - Thanh Hóa & 2012 & 1.84 & 0.016 & -1.901 & 1.916 & -0.076 \\
\hline 9 & Mữi Né-Phan Thiết & 2012 & 2.13 & 0.146 & -1.807 & 1.953 & 0.177 \\
\hline 10 & Trạm BP Bình Hài-Q. Ngãi & 2013 & 1.19 & 0.087 & -0.824 & 0.911 & 0.279 \\
\hline 11 & Cảng Đông Hải-Lý Sơn & 2013 & 1.19 & 0.110 & -0.797 & 0.907 & 0.283 \\
\hline 12 & Tam Quan-Bình Định & 2013 & 1.22 & 0.068 & -1.107 & 1.175 & 0.045 \\
\hline 13 & Mữi Kê Gà-Bình Thuận & 2013 & 2.19 & 0.179 & -1.857 & 2.036 & 0.154 \\
\hline 14 & Cửa Đại-Quảng Nam & 2014 & 0.90 & -0.025 & -0.791 & 0.766 & 0.134 \\
\hline 15 & Hòn Mê-Thanh Hóa & 2014 & 1.70 & -0.025 & -1.882 & 1.857 & -0.157 \\
\hline 16 & Củ Lao Chàm & 2014 & 0.71 & -0.045 & -0.557 & 0.512 & 0.198 \\
\hline 17 & Hòn Chim & 2014 & 1.33 & 0.102 & -1.361 & 1.462 & -0.132 \\
\hline 18 & Hòn La - Quàng Bình & 2015 & 1.08 & 0.071 & -1.295 & 1.366 & -0.286 \\
\hline 19 & Hòn Mắt - Nghệ An & 2015 & 1.65 & 0.046 & -1.687 & 1.734 & -0.084 \\
\hline 20 & Cảng Hải đội 512 Phú Quốc & 2015 & 0.71 & -0.139 & -0.734 & 0.594 & 0.116 \\
\hline 21 & Cửa Việt - Quàng Trị & 2015 & 0.79 & -0.184 & -0.690 & 0.506 & 0.284 \\
\hline 22 & Cửa Hội - Nghệ An & 2015 & 1.65 & 0.025 & -1.703 & 1.728 & -0.078 \\
\hline 23 & Cửa Ba Lạt & 2015 & 1.92 & 0.117 & -2.188 & 2.306 & -0.386 \\
\hline 24 & Tam Quan - Bình Định & 2015 & 1.22 & 0.068 & -1.107 & 1.175 & 0.045 \\
\hline 25 & Cảng 2 - Đà Nẫng & 2015 & 0.90 & 0.030 & -0.753 & 0.784 & 0.116 \\
\hline 26 & Hòn Mê - Thanh Hóa & 2015 & 1.70 & -0.025 & -1.782 & 1.757 & -0.057 \\
\hline 27 & Lại Sơn - Kiên Giang & 2015 & 0.76 & -0.045 & -0.657 & 0.612 & 0.148 \\
\hline 28 & Sầm Sơn - Thanh Hóa & 2015 & 1.62 & -0.057 & -1.846 & 1.789 & -0.169 \\
\hline 29 & Sa Kỳ - Quảng Ngãi & 2015 & 1.19 & 0.094 & -0.913 & 1.007 & 0.183 \\
\hline 30 & Bạch Long Vì & 2016 & 1.85 & 0.009 & -1.929 & 1.939 & -0.089 \\
\hline 31 & Phúc Tần C-DK1 & 2016 & 1.18 & 0.207 & -0.913 & 1.120 & 0.060 \\
\hline 32 & Song Tử Tây & 2016 & 1.04 & 0.201 & -0.839 & 1.040 & 0.000 \\
\hline 33 & Lữ 127 - Phú Quốc & 2017 & 0.71 & -0.139 & -0.634 & 0.494 & 0.216 \\
\hline 34 & Hòn Chuối- Cà Mau & 2017 & 0.76 & 0.009 & -0.648 & 0.656 & 0.104 \\
\hline 35 & Cảng Cá - Côn Đào & 2017 & 2.29 & -0.056 & -2.291 & 2.235 & 0.055 \\
\hline 36 & DK $1-10$ & 2017 & 0.76 & 0.201 & -0.596 & 0.797 & -0.037 \\
\hline 37 & Cam Ranh - Quốc vét & 2017 & 1.29 & 0.091 & -1.043 & 1.133 & 0.157 \\
\hline 38 & Thuyền Chài - Điểm A & 2017 & 1.18 & 0.194 & -0.972 & 1.167 & 0.013 \\
\hline 39 & Nam Yết - Trường Sa & 2017 & 0.93 & 0.187 & -0.742 & 0.930 & 0.000 \\
\hline 40 & Cảng Vùng 2 - Vũng Tàu & 2017 & 2.42 & -0.090 & -2.474 & 2.384 & 0.036 \\
\hline 41 & Tốc Tan - Trường Sa & 2017 & 1.18 & 0.195 & -0.804 & 0.999 & 0.181 \\
\hline 42 & Đá Lát - Trường Sa & 2017 & 1.18 & 0.212 & -0.938 & 1.150 & 0.030 \\
\hline 43 & Mũi Tấn - Bình Định & 2017 & 1.25 & -0.006 & -0.968 & 0.962 & 0.288 \\
\hline
\end{tabular}

Cơ sở dữ liệu của mô hình MBTNKV108 trên vùng biển Việt Nam là mạng lưới (grid) các ô chuẩn hình vuông với độ phân giải 1'x 1' với các đỉnh của các ô chuẩn hình vuông bắt đầu từ vĩ tuyến $24^{\circ}$ thay đổi với bước nhảy $\Delta \mathrm{B}=1^{\prime}$ ' cho đến vĩ tuyến $7^{0}$. Tại một vĩ tuyến xác định, các đỉnh lại được bố trí theo kinh tuyến bắt đầu từ kinh tuyến $100^{\circ}$ thay đổi với bước nhảy $\Delta L=1$, cho đến kinh tuyến $116^{\circ}$. Trong phạm vi Biển
Đông bao trùm vùng biển Việt Nam có tất cả 18.109 đỉnh của các ô chuẩn. Các dữ liệu trên một đỉnh của ô chuẩn hình vuông bao gồm: giá trị $\mathrm{L}, \mathrm{B}, \mathrm{MBTNKV108}$ với kinh độ trắc địa $\mathrm{L}$ và vĩ độ trắc địa $\mathrm{B}$ được xác định trong hệ tọa độ WGS84 quốc tế.

2.4. Đánh giá độ chính xác độ chênh giữa mô hình MDTTBKV và mô hình MBTNKV108 
Sử dụng 23 điểm có độ chênh đo giữa mặt biển trung bình và mặt biển thấp nhất khu vực của Đoàn 6 không tham gia xây dựng mô hình MBTNKV108 (các điểm kiểm tra trong công trình [5]) để đánh giá độ chính xác của độ chênh giữa mô hình MDTTBKV và mô hình MBTNKV108. Kết quả đánh giá độ chính xác được thể hiện trong bảng 3 .

Kết quả kiểm tra sai số hệ thống

$$
A=\sum_{i=1}^{23} d_{i}=0.340 \mathrm{~m}, B=\sum_{i=1}^{23}\left|d_{i}\right|=3.703 \mathrm{~m} .
$$

Do $|A|=0.340<0.25 \times B=0.926$ nên trong hai dãy giá trị độ chênh (A0- $\pi 0)$ không chứa sai số hệ thống. Khi coi các độ chênh ( $\mathrm{A} 0-\pi 0$ đo) và (A0- $\pi 0$ tính theo mô hình) là hai dãy trị đo kép độc lập cùng độ chính xác, chúng ta đánh giá độ chính xác độ chênh giữa mô hình MDTTBKV và mô hình MBTNKV108 theo công thức:

$$
m_{(\mathrm{A} 0-\pi 0)}= \pm \sqrt{\frac{\sum_{i=1}^{23} d_{i}^{2}}{2.23}}= \pm \sqrt{\frac{0.8806}{46}}= \pm 0.138 \mathrm{~m} .
$$

Với tiêu chí xác định mặt biển trung bình tại trạm nghiệm triều tạm thời theo số liệu đo mực nước biển liên tục trong 30 ngày đêm với sai số trung phương ở mức $\pm 0.3 \mathrm{~m}$ [1], chúng ta có thể kết luận rằng các mô hình $\mathrm{MDTTBKV}$ và MBTNKV108 được xác định với độ chính xác rất cao.

So với kết quả đánh giá độ chính xác độ chênh giữa mô hình $\mathrm{MDTTBKV}$ và mô hình MBTNKV65 với độ chính xác \pm 0.157 m [5], mô hình MBTNKV108 với việc bổ sung thêm 43 trạm nghiệm triều đạt độ chính xác cao hơn $( \pm 0.138 \mathrm{~m})$.

\section{5. Đánh giá độ sâu bản đồ ĐHĐB và độ} sâu hải đồ dựa trên các mô hình MDTTBKV và MBTNKV108

a. Xác định độ sâu bản đồ $Đ H Đ B$ dụa vào độ sâu hải đồ và các mô hình MDTTBKV, MBTNKV108

Theo các quy định kỹ thuật, độ sâu bản đồ

Bảng 3: Kết quả đánh giá độ chính xác độ chênh giũa mô hình MDTTBKV

\begin{tabular}{|c|c|c|c|c|c|c|c|}
\hline Stt & Tên trạm & $\begin{array}{c}\text { Năm } \\
\text { đo }\end{array}$ & $\begin{array}{l}\mathrm{A} 0-\pi 0 \\
\text { đo }(\mathrm{m})\end{array}$ & $\begin{array}{c}\begin{array}{c}\text { MDTTBKV } \\
(\mathrm{m})\end{array} \\
\end{array}$ & $\begin{array}{c}\text { MBTNKH108 } \\
(\mathrm{m})\end{array}$ & $\begin{array}{c}\mathrm{A} 0-\pi 0 \\
\operatorname{tinh}(\mathrm{m})\end{array}$ & $\begin{array}{c}d_{i}= \\
(7)-(4)\end{array}$ \\
\hline (1) & (2) & (3) & (4) & (5) & (6) & (7) & (8) \\
\hline 1 & Cảng Vùng 3_Quy Nhơn & 2008 & 1.23 & -0.006 & -1.113 & 1.107 & 0.123 \\
\hline 2 & Sa Kỳ & 2004 & 1.12 & 0.094 & -0.956 & 1.050 & 0.070 \\
\hline 3 & Phú Quý & 2004 & 1.55 & 0.138 & -1.081 & 1.219 & 0.331 \\
\hline 4 & Côn Sơn & 2007 & 2.49 & -0.048 & -2.280 & 2.232 & 0.258 \\
\hline 5 & Gành Hào & 2004 & 2.68 & 0.064 & -2.838 & 2.901 & -0.221 \\
\hline 6 & Cầu Cảng BP S. Ông Đốc & 2001 & 0.695 & -0.026 & -0.813 & 0.787 & -0.092 \\
\hline 7 & Cửa Ông & 2007 & 2.17 & -0.001 & -2.142 & 2.141 & 0.029 \\
\hline 8 & Cát Bà & 2006 & 2.02 & -0.064 & -2.188 & 2.124 & -0.104 \\
\hline 9 & Cô Tô & 2008 & 2.18 & 0.112 & -1.986 & 2.099 & 0.081 \\
\hline 10 & Trạm Cửa Hội & 2008 & 1.71 & -0.063 & -2.075 & 2.012 & -0.302 \\
\hline 11 & Quy Nhơn & 2008 & 1.23 & -0.013 & -1.111 & 1.098 & 0.132 \\
\hline 12 & Cảng Nha Trang & 2008 & 1.22 & -0.041 & -0.994 & 0.953 & 0.267 \\
\hline 13 & Cam Ranh & 2008 & 1.29 & 0.106 & -1.184 & 1.290 & 0.000 \\
\hline 14 & Thuận An & 2005 & 0.38 & -0.174 & -0.450 & 0.276 & 0.104 \\
\hline 15 & Cầu cảng BP Ninh Chữ & 2010 & 1.358 & -0.004 & -1.110 & 1.106 & 0.252 \\
\hline 16 & Cầu cảng Phan Ri Cửa & 2010 & 1.772 & 0.035 & -1.919 & 1.953 & -0.181 \\
\hline 17 & Tân Cảng Quy Nhơn & 2010 & 0.731 & -0.024 & -1.050 & 1.026 & -0.296 \\
\hline 18 & Cảng Cửa Việt & 2011 & 0.522 & -0.284 & -0.872 & 0.588 & -0.066 \\
\hline 19 & Cửa Nhật Lệ & 2011 & 0.774 & -0.068 & -1.132 & 1.064 & -0.290 \\
\hline 20 & Cảng 2, Vùng 3 Đà Nẵng & 2011 & 0.766 & 0.030 & -0.765 & 0.795 & -0.029 \\
\hline 21 & Cảng Đông Tắc, Đà Giang & 2010 & 1.166 & -0.240 & -1.033 & 0.793 & 0.373 \\
\hline 22 & Đá Nam & 2006 & 0.98 & 0.197 & -0.841 & 1.038 & -0.058 \\
\hline \multirow[t]{2}{*}{23} & Phúc Tần & 2004 & 1.13 & 0.210 & -0.962 & 1.171 & -0.041 \\
\hline & & & & & & $\Sigma=$ & 0.340 \\
\hline
\end{tabular}
và mô hình MBTNKV108 
ĐHĐB được quy chiếu dựa trên mặt biển trung bình Hòn Dấu, trên cơ sở xác định độ cao HP72 cho trạm nghiệm triều của khu đo bằng phương pháp thủy chuẩn hình học hay GPS. Trong phạm vi khu đo nhỏ với tính chất thủy triều đồng nhất, sẽ chỉ sử dụng 01 trạm nghiệm triều. Số trạm nghiệm triều tăng lên tùy thuộc vào tính chất triều trong toàn bộ phạm vi khu đo. Độ sâu hải đồ được quy chiếu dựa trên mực nước triều thiên văn thấp nhất tại trạm nghiệm triều được xác định theo phương pháp hải văn. Tuy nhiên trong thực tế, mực nước triều thiên văn thấp nhất tại trạm nghiệm triều được xác định bằng độ chênh giữa mực nước biển trung bình và mực nước triều thiên văn thấp nhất (A0- $\pi 0)$. Như vậy, cả độ sâu dựa trên mặt nước biển trung bình và độ sâu dựa trên mực nước triều thiên văn thấp nhất đều được quy chiếu lên một mặt phẳng cho khu đo sử dụng một trạm nghiệm triều. Khi tiếp biên các khu đo có các trạm nghiệm triều khác nhau, độ sâu tại khu vực tiếp biên được "làm khớp" dựa vào đánh giá chủ quan của các biên tập viên nội nghiệp. Điều này dẫn tới nhiều sai sót trong độ sâu đo tại các khu vực tiếp biên, nhất là ở những khu vực cạnh nhau với hai vùng triều có tính chất khác nhau. Uu điểm của việc quy chiếu các trị đo sâu dựa trên các mô hình mặt biển là xác định chính xác độ cao của mặt biển tham chiếu tại từng vị trí "đọ" độ sâu và không phải tiếp biên các khu đo với tính chất triều khác nhau, đồng thời tạo điều kiện thuận lợi khi giải quyết bài toán sử dụng dữ liệu đo sâu ĐHĐB cho các mục đích khác nhau.

Từ các phân tích ở trên ta thấy rằng, ngoài việc quy chiếu độ sâu ĐHĐB dựa trên độ cao nhà nước tại các trạm nghiệm triều, độ sâu bản đồ ĐHĐB còn được tính theo công thức:

$$
\mathrm{h}_{\mathrm{BDDH}}=\mathrm{h}_{\mathrm{HD}}+(\mathrm{A} 0-\pi 0)
$$

trong đó $\mathrm{h}_{\mathrm{BDDH}}$ là độ sâu bản đồ ĐHĐB dựa trên mặt biển trung bình; $\mathrm{h}_{\mathrm{HD}}$ là độ sâu hải đồ dựa trên mực nước triều thiên văn thấp nhất; A0 là độ cao mặt biển trung bình và $\pi 0$ là độ cao mặt biển thấp nhất tại cùng một trạm nghiệm triều.
Xác định độ sâu bản đồ ĐHĐB từ độ sâu hải đồ là bài toán khoa học kỹ thuật quan trọng trong bối cảnh bản đồ ĐHĐB mới chỉ phủ kín khoảng $20 \%$ diện tích vùng biển Việt Nam. Tuy nhiên, xác định độ sâu bản đồ ĐHĐB từ độ sâu hải đồ khi sử dụng công thức (1) gặp rất nhiều khó khăn do trên các mảnh hải đồ không xác định được độ chênh (A0- $\pi 0)$

Trong trường hợp quy chiếu độ sâu bản đồ ĐHĐB và độ sâu hải đồ dựa trên các mô hình mặt biển, tương tự công thức (1), ta có:

$$
\mathrm{h}_{\mathrm{BDDH}}=\mathrm{h}_{\mathrm{HD}}+(\text { MDTTBKV-MBTNKV108) }
$$

với MDTTBKV là độ cao mặt biển trung bình được xác định từ mô hình MDTTBKV, còn MBTNKV108 là độ cao mặt biển thấp nhất được xác định từ mô hình MBTNKV108 tại vị trí quy chiếu trị đo sâu.

Sử dụng công thức (2) chúng ta có thể xác định một cách tin cậy độ sâu bản đồ ĐHĐB từ độ sâu hải đồ dựa vào các mô hình mặt biển MDTTBKV và MBTNKV108.

\section{b. Xác định độ sâu bản đồ $Đ H Đ B$ tù độ sâu hải đồ}

Để thấy rõ vai trò to lớn của các mô hình mặt biển đã được xây dựng, chúng tôi tiến hành đánh giá độ sâu bản đồ ĐHĐB và độ sâu hải đồ. Các ứng dụng khác của các mô hình mặt biển sẽ được chúng tôi công bố trên các công trình tiếp theo.

Từ độ sâu hải đồ, dựa vào phần mềm ArcGis để thiết lập mô hình $\mathrm{DEM}$ và xác định được độ sâu hải đồ tại các điểm có độ sâu bản đồ ĐHĐB, độ cao mặt biển trung bình từ mô hình MDTTBKV, độ cao mặt biển thấp nhất từ mô hình MBTNKV108 và độ sâu bản đồ ĐHĐB theo công thức (2).

Lựa chọn 04 mảnh bản đồ ĐHĐB nằm trong 04 mảnh hải đồ phân bố đều dọc bờ biển Việt Nam (xem hình 2). Tiến hành tính toán độ sâu bản đồ ĐHĐB cho mảnh bản đồ ĐHĐB C-4877-B (5826 I) tại vị trí của 881 điểm độ sâu chi tiết từ độ sâu hải đồ của mảnh hải đồ IA-100-29. Kết quả tính toán được trình bày trong bảng 4 . 
Bảng 4: Kết quả tính toán độ sâu bản đồ ĐHĐB tù độ sâu hải đồ

\begin{tabular}{|c|c|c|c|c|c|c|c|c|c|c|}
\hline Stt & $\begin{array}{c}\mathbf{Y} \\
(\mathbf{m})\end{array}$ & $\underset{(\mathrm{m})}{\mathbf{X}}$ & $\begin{array}{c}\mathbf{h}_{\mathrm{B \boxminus \oplus H}} \\
(\mathbf{m})\end{array}$ & $\begin{array}{c}\mathbf{h}_{\text {HP-DEM }} \\
(\mathbf{m})\end{array}$ & $\begin{array}{c}\text { A0 } \\
\text { (MDTTBKV) } \\
\text { (m) }\end{array}$ & $\begin{array}{c}\pi 0 \\
\text { (MBTNKV108) } \\
(\mathrm{m})\end{array}$ & $\begin{array}{c}\text { Độ chênh } \\
\text { (A0- } \pi 0)_{\mathrm{i}} \\
\text { (m) }\end{array}$ & $\begin{array}{c}\mathbf{h}_{\mathrm{BD \oplus H}-\mathrm{tinh}} \\
=(\mathbf{5})+(\mathbf{8}) \\
\text { (m) }\end{array}$ & $\begin{array}{c}\text { Độ lệch } \\
\mathrm{d}_{\mathrm{i}}=(\mathbf{9})- \\
\text { (4) } \\
(\mathrm{m}) \\
\end{array}$ & $\begin{array}{c}\varepsilon_{\mathrm{i}}= \\
\mathbf{d}_{\mathrm{i}}-\delta_{\mathrm{tb}}\end{array}$ \\
\hline (1) & $(2)$ & (3) & (4) & (5) & $(6)$ & (7) & (8) & (9) & (10) & (11) \\
\hline 1 & 417383.9 & 991945.9 & 27.0 & 26.749 & 0.056 & -0.492 & 0.548 & 27.297 & -0.297 & -0.851 \\
\hline 2 & 417560.6 & 983436.2 & 25.5 & 24.166 & 0.065 & -0.532 & 0.597 & 24.763 & 0.737 & 0.183 \\
\hline 3 & 418359.1 & 983437.5 & 24.2 & 23.808 & 0.065 & -0.532 & 0.597 & 24.405 & -0.205 & -0.760 \\
\hline 4 & 417882.0 & 984429.2 & 24.9 & 24.180 & 0.065 & -0.532 & 0.597 & 24.777 & 0.123 & -0.431 \\
\hline 5 & 419157.6 & 983438.5 & 26.1 & 25.433 & 0.062 & -0.548 & 0.609 & 26.042 & 0.058 & -0.496 \\
\hline 6 & 421546.2 & 983417.6 & 23.6 & 22.390 & 0.058 & -0.564 & 0.622 & 23.012 & 0.588 & 0.034 \\
\hline$\ldots$ & $\ldots$ & $\ldots$ & $\cdots$ & $\ldots$ & $\ldots$ & $\ldots$ & $\ldots$ & $\ldots$ & $\ldots$ & $\ldots$ \\
\hline 400 & 440122.5 & 994420.5 & 24.7 & 24.339 & 0.014 & -0.657 & 0.671 & 25.010 & -0.310 & -0.864 \\
\hline 401 & 440819.1 & 991414.9 & 25.1 & 23.000 & 0.015 & -0.706 & 0.721 & 23.721 & 1.379 & 0.825 \\
\hline 402 & 441618.2 & 991417.5 & 24.6 & 23.000 & 0.015 & -0.706 & 0.721 & 23.721 & 0.879 & 0.325 \\
\hline 403 & 441918.7 & 992408.6 & 24.7 & 23.310 & 0.013 & -0.688 & 0.701 & 24.012 & 0.688 & 0.134 \\
\hline 404 & 441118.6 & 992410.7 & 24.7 & 23.151 & 0.013 & -0.688 & 0.701 & 23.853 & 0.847 & 0.293 \\
\hline$\ldots$ & $\ldots$ & $\ldots$ & $\ldots$ & $\ldots$ & $\ldots$ & $\ldots$ & $\ldots$ & $\ldots$ & $\ldots$ & $\ldots$ \\
\hline 877 & 426694.7 & 979958.8 & 21.6 & 20.818 & 0.052 & -0.641 & 0.693 & 21.511 & 0.089 & -0.463 \\
\hline 878 & 427526.5 & 980937.3 & 22.3 & 21.580 & 0.052 & -0.641 & 0.693 & 22.274 & 0.026 & -0.526 \\
\hline 879 & 430419.5 & 980919.1 & 24.6 & 23.530 & 0.046 & -0.681 & 0.727 & 24.257 & 0.343 & -0.209 \\
\hline 880 & 430681.5 & 980429.1 & 25.6 & 24.580 & 0.046 & -0.681 & 0.727 & 25.307 & 0.293 & -0.259 \\
\hline 881 & 427227.4 & 980919.4 & 22.1 & 20.681 & 0.052 & -0.641 & 0.693 & 21.374 & 0.726 & 0.174 \\
\hline & & & & & & & & $\Sigma=$ & 486.338 & \\
\hline
\end{tabular}

Tính toán tương tự cho 03 mảnh bản đồ ĐHĐB C-49-26-B, E-49-86-C và F-48-84-C, tương ứng với các mảnh hải đồ IA-100-20, IA$100-12$ và $\mathrm{IA}-100-02$.

c. Đánh giá kết quả xác định độ sâu bản đồ $Ð H Đ B$ tì độ sâu hải đồ

Xem độ sâu bản đồ ĐHĐB đo và độ sâu bản đồ ĐHĐB tính theo mô hình (bảng 4) là hai dãy trị đo độc lập với nhau và tiến hành đánh giá độ chính xác. Kết quả kiểm tra sai số hệ thống

$$
\mathrm{A}=\sum_{\mathrm{i}=1}^{881} \mathrm{~d}_{\mathrm{i}}=486.338 \mathrm{~m}, \mathrm{~B}=\sum_{\mathrm{i}=1}^{881}\left|\mathrm{~d}_{\mathrm{i}}\right|=634.948 \mathrm{~m} \text {. }
$$

Do $|\mathrm{A}|=486.338>0.25 \times \mathrm{B}=158.737$, nên trong hai dãy trị đo ở trên có chứa sai số hệ thống. Tiến hành khử sai số hệ thống theo phương pháp Besel:

- Tính số hiệu chỉnh

$$
\delta_{\mathrm{tb}}=\frac{[\mathrm{d}]}{\mathrm{n}}=0.552 \mathrm{~m}
$$

- Khử sai số hệ thống khỏi hiệu $\mathrm{d}_{\mathrm{i}}$ theo công thức:

$$
\varepsilon_{\mathrm{i}}=\mathrm{d}_{\mathrm{i}}-\delta_{\mathrm{tb}}
$$

Kết quả kiểm tra sau khi khử sai số hệ thống, trong các hiệu $\mathrm{d}_{\mathrm{i}}$ không còn chứa sai số hệ thống.

- Tính sai số trung phương theo công thức:

$$
\mathrm{m}_{\mathrm{ds} \_ \text {BDDH }}= \pm \sqrt{\frac{[\varepsilon \varepsilon]}{2(\mathrm{n}-1)}}=\sqrt{\frac{413.474}{2.880}} \pm 0.485 \mathrm{~m}
$$

Bằng cách như vậy chúng ta đánh giá kết quả tính độ sâu bản đồ ĐHĐB từ độ sâu hải đồ cho 03 mảnh bản đồ ĐHĐB còn lại và nhận được sai số trung phương độ sâu bản đồ ĐHĐB tương ứng:

- Mảnh bản đồ ĐHĐB C-49-26-B:

$$
\mathrm{m}_{\mathrm{ds} \_ \text {BDDH }}= \pm 2.078 \mathrm{~m}
$$

- Mảnh bản đồ ĐHĐB E-49-86-C:

$$
\mathrm{m}_{\mathrm{ds} \_ \text {BDDH }}= \pm 1.348 \mathrm{~m}
$$

- Mảnh bản đồ ĐHĐB F-48-84-C:

$$
\mathrm{m}_{\mathrm{ds} \_ \text {BDDH }}= \pm 0.978 \mathrm{~m}
$$

\section{d. Phân tích kết quả đánh giá}

Kết quả đánh giá độ sâu bản đồ ĐHĐB cho mảnh bản đồ ĐHĐB C-48-77-B từ độ sâu hải đồ 
của mảnh hải đồ IA-100-29 cho thấy, sử dụng các mô hình mặt biển MDTTBKV và MBTNKV108 để tính độ sâu bản đồ ĐHĐB từ độ sâu hải đồ hoàn toàn đáp ứng yêu cầu về độ chính xác theo các tiêu chuẩn quy định $[1,2]$. Tuy nhiên, để xác định được độ sâu bản đồ ĐHĐB từ độ sâu hải đồ đảm bảo độ chính xác thì còn phụ thuộc vào nhiều yếu tố. Để làm rõ vấn đề này, chúng ta lần lượt phân tích kết quả đánh giá độ chính xác độ sâu bản đồ ĐHĐB được xác định từ từ độ sâu hải đồ cho 03 mảnh bản đồ ĐHĐB còn lại.

- Các mảnh bản đồ ĐHĐB C-49-26-B và F48-84-C: Địa hình đáy biển biến đổi rất phức tạp nên các điểm độ sâu trên hải đồ tỷ lệ $1: 100.000$ không đủ mật độ để đảm bảo độ chính xác của DEM trong việc xác định độ sâu bản đồ ĐHĐB tỷ lệ 1:50.000. Để khắc phục vấn đề này, chúng tôi giải bài toán ngược lại: Thành lập DEM từ các điểm độ sâu bản đồ ĐHĐB và xác định độ sâu bản đồ ĐHĐB tại các điểm có độ sâu hải đồ, tuy nhiên độ chính xác không được cải thiện đáng kể.

- Toàn bộ độ sâu trên mảnh bản đồ ĐHĐB E49-86-C đều nhỏ hơn độ sâu trên mảnh hải đồ IA-100-12 tương ứng (xem hình 4), mặc dù khu đo thuộc các trạm nghiệm triều Tiên Sa - Sơn Trà và Cửa Đại - Quảng Nam (hình 5 ) với độ chênh giữa mặt biển trung bình và mặt biển thấp nhất (A0-p0) khoảng $70 \mathrm{~cm}$ (xem bảng 5). Điều này mâu thuẫn với quy định về cơ sở toán học của bản đồ ĐHĐB và hải đồ: Tại mọi vị trí, độ sâu bản đồ ĐHĐB phải luôn không nhỏ hơn độ sâu hải đồ.

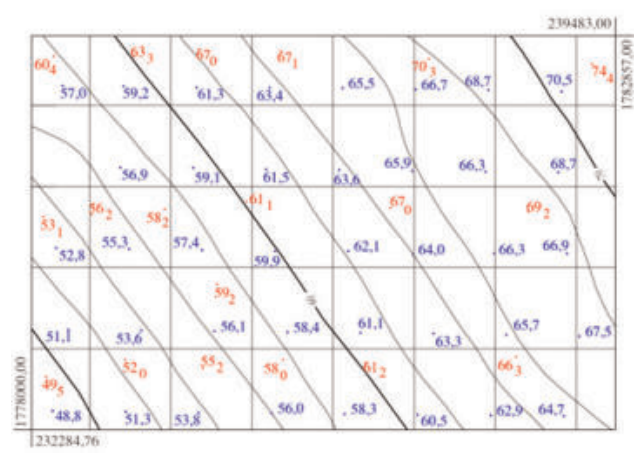

Hình 4: Độ sâu ĐHĐB:
Màu đỏ: Độ sâu trên hải đồ

Màu xanh: Độ sâu trên bản đồ ĐHĐB

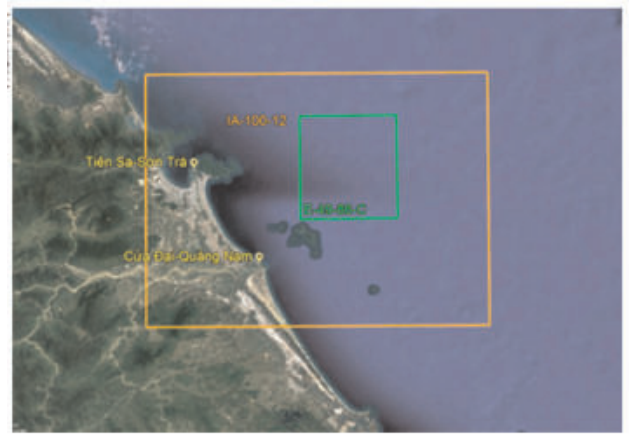

Hình 5: So đồ vị trí các trải nghiệm triều xung quanh mảnh hải đồ IA-100-12 và mảnh bản đồ $Ð N Ð B$ E-49-86-C

Bảng 5: Độ chênh giữa mặt biển trung bình và mặt biển thấp nhất tại các trạm nghiệm triều khu vưc của mảnh bản đồ ĐHĐB C-49-26-B và mảnh hải đồ IA-100-20

\begin{tabular}{|c|l|c|c|}
\hline Stt & \multicolumn{1}{|c|}{$\begin{array}{c}\text { Tên trạm } \\
\text { nghiệm triều }\end{array}$} & $\begin{array}{c}\text { Độ chênh } \mathbf{A}_{0}-\boldsymbol{\pi}_{\mathbf{0}} \\
\text { (m) }\end{array}$ & Năm đo \\
\hline 1 & Tiên Sa - Sơn Trà & 0.65 & $2014[5]$ \\
\hline 2 & $\begin{array}{l}\text { Cừa Đại - Quàng } \\
\text { Nam }\end{array}$ & 0.766 & $\begin{array}{c}2014 \text { (bảng } \\
\text { 2) }\end{array}$ \\
\hline & Trung bình & 0.72 & \\
\hline
\end{tabular}

Khó khăn trong việc đánh giá dữ liệu độ sâu bản đồ ĐHĐB và độ sâu hải đồ là không có được bản đồ ĐHĐB và hải đồ cùng tỷ lệ. Tuy nhiên, cơ sở khoa học và phương pháp được phát triển chặt chẽ, đảm bảo độ tin cậy của kết quả.

Từ kết quả đánh giá độ sâu bản đồ ĐHĐB và độ sâu hải đồ cho 04 khu vực nêu trên có thể kết luận rằng với hiện trạng bản đồ $\mathrm{DHĐB} \mathrm{và} \mathrm{hải} \mathrm{đồ}$ của Việt Nam, không thể tính toán độ sâu bản đồ ĐHĐB từ độ sâu hải đồ đảm bảo độ chính xác theo yêu cầu.

\section{Kết luận}

Các kết quả đánh giá độ sâu bản đồ ĐHĐB và hải đồ đã khẳng định ưu thế vượt trội của các mô hình MDTTBKV và MBTNKV108. Với hiện trạng độ sâu bản đồ ĐHĐB và hải đồ được quy chiếu dựa trên mặt biển trung bình và mặt biển thấp nhất tại các trạm nghiệm triều sẽ không thể 
có được phương pháp thích hợp để tính toán độ sâu bản đồ ĐHĐB từ độ sâu hải đồ cho toàn bộ vùng biển Việt Nam đảm bảo độ chính xác theo các quy định kỹ thuật hiện hành. Cần phải nhanh chóng đưa các mô hình MDTTBKV và MBTNKV108 vào thực tế sản xuất cho phù hợp với sự phát triển của khoa học công nghệ thế giới hiện đại. Các vấn đề khoa học kỹ thuật liên quan đến quy chiếu trị đo sâu dựa trên các mô hình mặt biển sẽ được chúng tôi công bố trong các công trình tiếp theo./. $\mathrm{O}$

\section{Tài liệu tham khảo}

[1]. Bộ Khoa học và Công nghệ, (2015). Hải đồ vùng nước cảng biển và luồng hàng hải - Yêu cầu kỹ thuật cho hải đồ giấy - Ký hiệu. Tiêu chuẩn quốc gia TCVN 10337:2015.

[2]. Bộ Tài nguyên và Môi trường, (2007). Quyết địnhban hành quy định kỹ thuật thành lập bản đồ địa hình đáy biển tỷ lệ 1: 50 000, số
03/2007/QĐ-BTNMT, ngày 12-02-2007. Hà Nội.

[3]. Đoàn Đo đạc Biên vẽ hải đồ và Nghiên cứu biển, (2017). Thông tin về hệ thống bản đồ biển. Hải Phòng.

[4]. Hà Minh Hòa, (2015). Nghiên cứu đánh giá các mặt chuẩn mực nước biển (mặt " 0 ” độ sâu, trung bình và cao nhất) theo các phương pháp trắc địa, hải văn và kiến tạo hiện đại phục vụ xây dựng các công trình và quy hoạch đới bờ Việt Nam trong xu thế biến đổi khí hậu. Báo cáo tổng hợp kết quả đề tài NCKH cấp Nhà nước.Mã số KC.09.19/11-15. Bộ Khoa học và Công nghệ.

[5]. Khương Văn Long, Lương Thanh Thạch, Trần Văn Hải, Đặng Xuân Thưy (2018). Xây dựng mô hình mặt biển trung bình và mặt biển thấp nhất khu vực trên vùng biển Việt Nam. Tạp chí Khoa học Đo đạc và Bản đồ, số 37, tháng 92018, trg. 20-32. ○

\section{Summary}

\section{Evaluation of the depth of seabed's topographic mapand nautical chart based on sea sur- face model}

Luong Thanh Thach

Hanoi University of Natural Resources and Environment

Tran Van Hai

Survey Enterprise, Survey and Aerial mapping onememberLtd. Company

Nguyen Thi Hong

Vietnam Maritime University

Do Van Mong

\section{Department of Maritime Mapping and Maritime Studies}

This scientific article presents the results ofbuilding the lowest sea surface model in the region in Vietnam waters and uses regional average sea surface model and regional lowest sea surface model to assess the suitability between the depth data of the seabed topographic map and the depth ofnautical charts in the problem of measuringthe depth of the seabed's topographic mapbased on the depth of nautical chart. $\mathrm{O}$ 